\title{
Analysis of Flow Angularity Repeatability Tests in the NTF
}

\author{
Michael J. Hemsch ${ }^{*}$ \\ NASA Langley Research Center, Hampton, VA, 23681-2199
}

\begin{abstract}
An extensive data base of flow angularity repeatability measurements from four NTF check standard model tests is analyzed for statistical consistency and to characterize the results for prediction of angle-of-attack uncertainty for customer tests. A procedure for quality assurance for flow angularity measurements during customer tests is also presented. The efficacy of the procedure is tested using results from a customer test.
\end{abstract}

\section{Nomenclature}

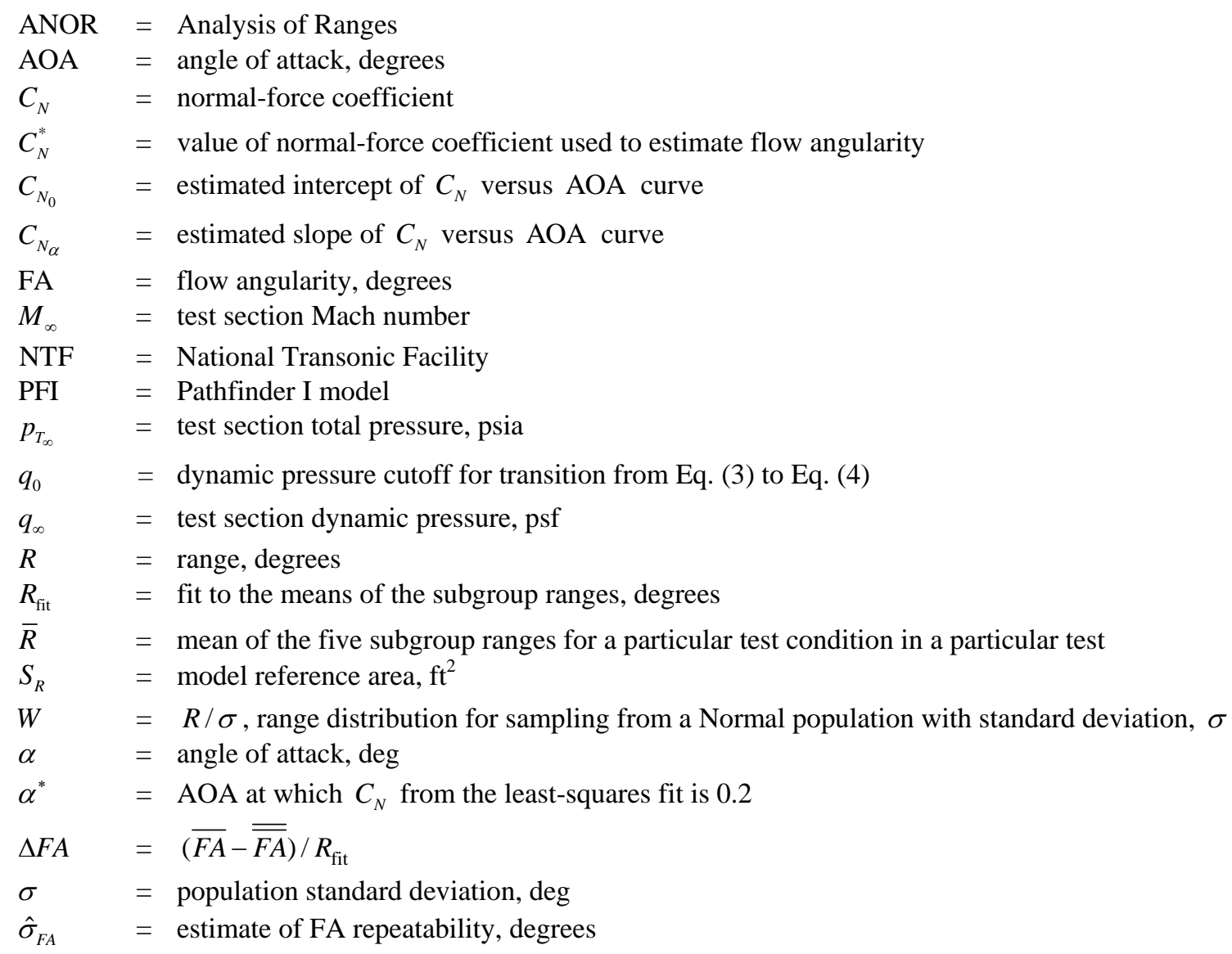

\section{Introduction}

ality assurance for wind tunnel measurements depends on two elements: (1) a clear, quantitative statement of the measurement uncertainty requirements and (2) a process for assuring that those requirements have been met for the test in question. For element (1), over the last few decades, it has been generally accepted that the total uncertainty for corrected angle-of-attack (AOA) measurements for performance testing of subsonic transport models

\footnotetext{
* Aerospace Technologist, Quality Assurance, Configuration Aerodynamics Branch, MS 499, Associate Fellow.
} 
at cruise conditions using an internal balance should not be greater than 0.01 degrees. ${ }^{1}$ This value usually determines the AOA measurement capability that is required for a transonic tunnel. ${ }^{\dagger}$

For the second element, it is necessary to determine the major sources of uncertainty and develop a quality assurance process for each that meets the desired uncertainty goals. A typical corrected wind tunnel AOA measurement includes the following sources of uncertainty:

1) orientation of model reference surface to waterline (fossilized)

2) laboratory (off-line) calibration of the reference-to-gravity AOA instrument (fossilized)

3) in-test-section calibration of the on-board AOA instrument using the reference instrument (fossilized)

4) repeatability of the on-board AOA instrument under test conditions

5) correction for the effect of model dynamics on inertial AOA instruments

6) correction for the test section flow angularity (FA)

7) correction to "free-air conditions" for the effect of the test section boundaries

Source 1 is usually dealt with in the geometry quality assurance laboratory. Discussions of uncertainty sources 2 to 5 for the National Transonic Facility (NTF) are presented in Refs. 2-6. A discussion of uncertainty source 7 for the NTF is presented in Ref. 7. This paper presents a statistical analysis and characterization of extensive FA repeatability measurements (uncertainty source 6) obtained in the NTF, together with recommendations for a quality assurance process for FA measurements in customer tests. Such a process would include

a) characterization of the measurement process

b) evidence that the characterization is not changing with time

c) evidence that the characterization adequately predicts the process behavior for a customer test. ${ }^{8}$

This paper will not present results for the flow angularity itself which is a function of test conditions and, probably, environmental conditions as well as time. Rather, it presents results for the performance of the flow angularity measurement process.

\section{The Flow Angularity Measurement Process}

Four check standard model ${ }^{\ddagger}$ tests $(121,137,149,156)$ were conducted in the NTF to measure the repeatability ${ }^{\S}$ of various measurements, including test section FA. The NTF check standard model is the Pathfinder I (PFI) shown in Fig. 1. The NTF 113C force balance was used. Descriptions of the NTF, which is a closed-circuit, pressure, air and cryogenic nitrogen, ventilated transonic tunnel, are given in Refs. 11 and 12. The conditions for the repeatability tests were originally chosen to reasonably span the available test conditions in the facility while being limited to testing in the air mode to limit costs. As more was learned about the repeatability behavior, additional conditions were added and others dropped. The conditions for the four tests are given in Table 1.

To measure FA, back-to-back upright and inverted runs were made in the linear range of the normal-force coefficient $\left(C_{N}\right)$ versus angle of attack (AOA) curve. ${ }^{* *}$ For the FA measurements, the AOA range was -2.0 deg to 2.5 deg. A linear least-squares fit was applied to each curve and each linear equation was solved for the angle of attack, $\alpha^{*}$, at which the normal-force coefficient, $C_{N}^{*}$, was equal to 0.2 which is roughly in the middle of the fitted range. The flow angularity is then given by ${ }^{8}$

$$
\mathrm{FA}=0.5\left(\alpha_{\text {inverted }}^{*}-\alpha_{\text {upright }}^{*}\right)
$$

where

$$
\alpha^{*}=\left(C_{N}^{*}-C_{N_{0}}\right) / C_{N_{\alpha}}
$$

and the terms $C_{N_{0}}$ and $C_{N_{\alpha}}$ are the estimated intercept and slope of the fit. A typical example is given in Fig. 2.

\footnotetext{
${ }^{\dagger}$ For a typical subsonic transport tested with an internal balance, an AOA error of 0.01 degree translates to a drag coefficient error of one count.

${ }^{\ddagger}$ A check standard is defined as a standard artifact that is held constant over time and is used for periodic verification of a measurement process. ${ }^{9}$

$\S$ For the purposes of this paper, repeatability is defined as "closeness of the agreement between the results of successive measurements of the same measurand carried out under the same conditions of measurement.” It is usually expressed as a standard deviation. ${ }^{9,10}$

*** The model and sting can be rolled remotely on the test section mounting system as shown in Fig. 1.
} 
For tests 121 and 137, a set of five back-to-back runs were obtained for a given condition. This set was then repeated five times throughout the test for each condition. The order of the runs was (1) inverted, (2) upright, (3) upright, (4) upright, (5) inverted. Runs 1 and 2 and runs 4 and 5 gave two FA measurements over a short time constituting what will be called a subgroup. For test 149, groups of three back-to-back runs were made for each condition and repeated five times throughout the test. The order of the runs was (1) upright, (2) inverted, (3) upright. Runs 1 and 2 and runs 2 and 3 were used to obtain the two FA measurements constituting a subgroup. For test 156, groups of four back-to-back runs were made for each condition and repeated five times throughout the test. The order of the runs was (1) upright, (2) inverted, (3) inverted, (4) upright. Runs 1 and 2 and runs 3 and 4 were used to obtain the two FA measurements constituting a subgroup. Hence, for each entry in Table 1, there were $10 \mathrm{FA}$ measurements divided into five subgroups with two observations each. Each subgroup provides one degree of freedom for estimating the repeatability, for a total of five degrees of freedom in each test for each condition. ${ }^{\dagger}$

\section{Repeatability Characterization}

\section{A. Fitting the Ranges}

The mean ranges, i.e. the averages of the ranges for the five subgroups, for each condition in each of the four tests are shown in Fig. 3 as symbols. The 31 mean ranges consist of 155 subgroups for a total of 155 degrees of freedom since each range represents two measurements. Since the FA measurement is determined by a fit to $C_{N}$ data, it would be expected that the dispersion of the FA measurements would depend directly on $\sigma_{C_{N}}$. In Ref. 13, it is shown that $\sigma_{C_{N}}$ for the check standard tests is inversely proportional to $q_{\infty}$ for $q_{\infty}$ less than roughly 400 psf and constant for $q_{\infty}$ greater than that. Indeed, the behavior of the mean ranges of Fig. 3 seems to be similar. The statistical analysis in the Appendix shows that the FA repeatability behavior would necessarily be similar to that of the normal-force coefficient, $C_{N}$. Hence, the fit should behave as follows:

$$
R_{\mathrm{fit}}=C_{1} / q_{\infty}
$$

for $q_{\infty} \leq q_{0}$ and

$$
R_{\text {fit }}=C_{2}
$$

for $q_{\infty}>q_{0}$ where $q_{0}$ is some transition value of $q_{\infty}$ and is probably dependent on the mounting system, including the balance. The constant, $C_{1}$, was found by averaging the $\bar{R} * q_{\infty}$ data for $q_{\infty} \leq 398 \mathrm{psf}$. The constant, $C_{2}$ was found by averaging the $\bar{R}$ data for $q_{\infty} \geq 398 \mathrm{psf}$. The resulting fits are

$$
\begin{gathered}
R_{\mathrm{fit}}=0.714 / q_{\infty} \mathrm{deg}-\mathrm{psf} \\
R_{\mathrm{fit}}=0.00246 \mathrm{deg}
\end{gathered}
$$

Equations (5, 6) are shown in Fig. 3 as solid lines. The lines meet at $q_{0}=290$ psf . Equations (5, 6), in effect, describe the means about which the subgroup ranges should be expected to scatter within bounds.

For transonic cruise performance testing which provides the most stringent AOA accuracy requirement, Eq. (6) will typically apply. For convenience in setting confidence limits, $R_{\text {fit }}$ can be used to estimate the (virtual) population standard deviation, $\hat{\sigma}$, as follows ${ }^{14}$

$$
\hat{\sigma}=R_{\mathrm{fit}} / 1.128=0.00218 \mathrm{deg}
$$

\footnotetext{
${ }^{{ }^{+}}$The FA depends weakly on the test condition and can vary slowly with time. Hence, it is necessary to separate the repeatability by considering only the back-to-back variation. Combining the groups to get more degrees of freedom would confound the test condition and time variations with the repeatability.
} 


\section{B. Analysis of the Ranges for Statistical Consistency}

Since the 155 individual ranges have now been fit, it is appropriate to determine if their scatter forms a reasonable frequency distribution. A single distribution for the whole range of test conditions can be obtained by dividing each subgroup range by the corresponding value of $R_{\mathrm{fit}}$ to obtain a normalized subgroup range, $R / R_{\mathrm{fit}}$. The resulting distribution of normalized subgroup ranges are shown in Fig. 4 for all 155 values, i.e for all of the values of $q_{\infty}$.The histogram is compared with what one would ideally expect from similar sampling from a Standard Normal distribution. A probability plot, based again on sampling from an ideal Standard Normal distribution, is given in Fig. 5. Figures 4 and 5 together indicate that the ranges are distributed reasonably but not precisely like the Normal ideal. Rather, the tail is fairly heavy. This type of behavior seems to be common in measurement processes and is discussed at length by Mosteller and Tukey. ${ }^{15}$ Their analysis suggests that the heavy tails for what would otherwise be a Normal distribution could be caused by a slight contamination of another Normally-distributed source of variation but with a considerably large population standard deviation. Fortunately, fitting the ranges rather than the variances is a more robust estimation process and the heavy tails do not present a problem for using the repeatability to estimate uncertainty.

Another type of test for statistical consistency ${ }^{\ddagger \ddagger}$ of a set of ranges is the Analysis of Ranges (ANOR) method described by Wheeler. ${ }^{16}$ For ANOR, the subgroup scatter bounds are determined by assuming that the population is Normal and homogeneous and using selected critical values as limits. ${ }^{\S \S}$ The method is fairly robust to outliers and distributional assumptions since it uses ranges rather than variances, as discussed above. The test for statistical consistency, i.e. for homogeneity, is then the number of ranges that fall outside the limits compared to what would be expected by chance (in the long run). For the purposes of this paper, it is convenient to use a lower critical value of zero and an upper critical value corresponding to a cumulative probability of 0.995 . This particular approach enables the separation of the scatter for each value of $q_{\infty}$. The results are shown in Figs. 6 and 7. Figure 6 shows that no particular value of $q_{\infty}$ can be singled out. Similarly, Fig. 7 shows that no particular test can be single out.

The fit itself is shown as the solid line with value one. The upper critical value is found as follows using the $W=R / \sigma$ distribution for sampling from a Normal distribution ${ }^{14}$ :

$$
\frac{R_{0.995}}{R_{\text {fit }}}=\frac{W_{0.995}}{W_{\text {fit }}}=\frac{3.970}{1.128}=3.52
$$

where the population mean of $\mathrm{W}$ for samples of size two is 1.128 and it is assumed to be given by $R_{\mathrm{fit}} / \sigma$ and where the upper critical value for a cumulative probability of 0.995 is $3.970 .{ }^{17}$ The upper critical value is shown in Figs. 6 and 7 as the dashed line. Since $0.005 * 155 \approx 1$, it is clear that there are far more ranges above the critical value than would be expected by chance for random sampling from a Normal distribution, suggesting the heavy tail.

\section{Within-Test Variation ${ }^{* * *}$}

\section{A. Comparison with Repeatability}

Proper examination of the FA within-test variation (reproducibility ${ }^{10}$ ) requires accounting for (1) the repeatability and (2) the variation of FA with test conditions and across tests. To do that, a new variable is defined:

$$
\Delta F A=(\overline{F A}-\overline{\overline{F A}}) / R_{\text {fit }}
$$

where $\overline{F A}$ is the average of the two FA values in any given subgroup and $\overline{\overline{F A}}$ is the grand average of the five subgroup averages at a given test condition in a given test. The new variable takes out the trending of both mean and scatter across tests and the test conditions and allows a comparison of reproducibility across all of the tests and all of the test conditions at once. Again, this is similar to creating a Standard Normal distribution. To account for variation in $\triangle F A$ that would be expected just due to repeatability, upper and lower limits (based on the repeatability) will be

\footnotetext{
\# Statistical consistency is defined to mean that the samples are drawn from a fixed population, albeit virtual.

$\S$ Actually, ANOR can be carried out with any distribution, as long as the critical values for the upper tail are known.

*** This section follows the approach suggested by Eisenhart. ${ }^{18}$
} 
computed similar to a two-sided hypothesis test ${ }^{14}$. A coverage range of $99 \%$ (Normal distribution) is selected in an attempt to avoid mistaking noise for a signal. ${ }^{\dagger+\dagger}$ The resulting limits are

$$
\Delta F A_{\text {limits }}= \pm 2.576 \hat{\sigma}_{\triangle F A}
$$

since the number of degrees of freedom is large. The standard deviation in Eq. (10) is found as follows. Consideration of Eq. (9) gives

$$
\hat{\sigma}_{\Delta F A}=\hat{\sigma}_{\overline{F A}} / R_{\text {fit }}
$$

But the average is composed of two values, so, if repeatability is the only source of variation, the standard deviation for the subgroup averages should be

$$
\hat{\sigma}_{\overline{F A}}=\sigma_{F A} / \sqrt{2}
$$

As pointed out in section III.B, $\hat{\sigma}_{F A}$ can be expressed in terms of $R_{\text {fit }}$ by

$$
\hat{\sigma}_{F A}=R_{\text {fit }} / 1.128
$$

Substituting Eqs. (11-13) into Eq. (10) gives

$$
\Delta F A_{\text {limits }}= \pm 2.576 \hat{\sigma}_{\Delta F A}= \pm 2.576 \frac{\hat{\sigma}_{\overline{F A}}}{R_{\text {fit }}}= \pm 2.576 \frac{\hat{\sigma}_{F A}}{\sqrt{2} R_{\text {fit }}}= \pm \frac{2.576}{1.128 \sqrt{2}}= \pm 1.615
$$

Since the $\overline{F A}$ subgroup averages have all been normalized by their corresponding values of $R_{\mathrm{fit}}$, the different test conditions will have identical limits.

The $\triangle F A$ values for each test condition for the four tests are shown together with the limits of Eq. (14) and the centerline of zero in Figs. 8-11 for tests 121, 137, 149 and 156 respectively. The region between the upper and lower limits in Figs 8-11, in effect, provides a noise band with which to compare the within-test FA subgroup averages. There are two features of Figs. 8-11 to be noted. First, it is clear from Fig. 10 that a significant drift downward occurred during test 149 . The average drop in $\overline{F A}$ values over the course of that test was roughly 0.015 degrees. ${ }^{\text {\#\# }}$ Second, the number of subgroup averages outside the predicted noise limits is roughly $25 \%$ of the total which is more than an order of magnitude larger than would be expected for the coverage factor chosen (1\%), suggesting that additional sources of variation are introduced over time or that the flow angularity meanders, slightly but measurably, over time.

\section{B. Within-Test Reproducibility}

The between-subgroup variation, $\hat{\sigma}_{\mathrm{BG}}$, is defined to be the additional scatter above that predicted by the repeatability. For the subgroup averages, $\overline{F A}$, the expression for $\hat{\sigma}_{\mathrm{BG}}$ is ${ }^{18}$

$$
\hat{\sigma}_{\mathrm{BG}}=\sqrt{\hat{\sigma}_{\Delta F A, \text { actual }}^{2}-\hat{\sigma}_{\Delta F A \text {, repeatability }}^{2}}
$$

The second term under the radical sign is found by combining Eqs. (11-13)

$$
\hat{\sigma}_{\triangle F A, \text { repeatability }}=\frac{\hat{\sigma}_{\overline{F A}}}{R_{\mathrm{fit}}}=\frac{\hat{\sigma}_{F A}}{\sqrt{2} R_{\mathrm{fit}}}=\frac{1}{1.128 \sqrt{2}}=0.6269
$$

\footnotetext{
${ }^{\mathrm{T \dagger}}$ Even using a strong confirmatory coverage range of 99.9\%, the limits only increase by roughly 25\% over those of Eq. (14).

\#䩸 The noise band in Figs. 8-11 is $\pm(0.00246)(1.615)= \pm 0.0040$ deg.
} 
The values of $\hat{\sigma}_{\triangle F A \text {, actual }}$ for each of the test conditions in tests 121, 137 and 156 are given in Table 1 . The values were averaged and corrected for the expected $6 \%$ bias $^{14}$ for samples of size five from a Normal distribution to get

$$
\hat{\sigma}_{\Delta F A, \text { actual }}=1.140
$$

Substitution of Eqs. $(16,17)$ into Eq. (15) gives $\hat{\sigma}_{\mathrm{BG}}=0.9522$.

An estimate of the increase in scatter that would be expected due to the not-insignificant value of reproducibility can be found as follows. The combined scatter is given by ${ }^{18}$

$$
\begin{aligned}
\hat{\sigma}_{\text {combined }} & =\sqrt{\hat{\sigma}_{\text {reproducibility }}^{2}+\hat{\sigma}_{\text {repeatability }}^{2}} \\
& =\sqrt{\hat{\sigma}_{\mathrm{BG}}^{2}+\left(\frac{\hat{\sigma}_{F A}}{R_{\mathrm{fit}}}\right)^{2}}=\frac{\hat{\sigma}_{F A}}{R_{\mathrm{fit}}} \sqrt{1+\frac{\hat{\sigma}_{\mathrm{BG}}^{2}}{\left(\hat{\sigma}_{F A} / R_{\mathrm{fit}}\right)^{2}}}=\frac{\hat{\sigma}_{F A}}{R_{\mathrm{fit}}} \sqrt{1+\left(\frac{0.9522}{1 / 1.128}\right)^{2}}=1.47 \frac{\hat{\sigma}_{F A}}{R_{\mathrm{fit}}}
\end{aligned}
$$

If the flow angularity is to be measured only once or a few times in a given test and steps have been taken to avoid the kind of drift seen in test 149, then Eq. (18) suggests that the within-test reproducibility could be estimated as roughly $50 \%$ greater than the predicted repeatability. But no statistical consistency test has been applied to the between-subgroup data. Also, since the within-test variation is likely to be much more dependent on procedures chosen for a particular test, the $50 \%$ increase should be treated as a rule of thumb only.

\section{Repeatability Prediction and Verification}

\section{A. Pathfinder I Tests}

For future check standard tests in the NTF with the Pathfinder I model and the NTF 113C balance, the expected mean range can be predicted with Eqs. $(5,6)$ as long as the measurement process remains essentially the same. The upper limit for a statistical control alarm would be given by the critical value of Eq. (8) and it would be expected that future range values for the FA measurement would fall about the predicted centerline with none above this limit. For quality assurance for the FA measurement process, the tunnel staff would obtain FA range measurements periodically throughout a check standard test and check them against the predicted centerline and upper limit values, plotting them against time during the test.

\section{B. Prediction for a Customer Test}

For future tests in the NTF with a different model but with the same (or equivalent) NTF balance, the expected mean range must be modified to account for a different reference area, $S_{R}$, and a different value of $C_{N_{\alpha}}$. A simple error propagation analysis ${ }^{19}$ of Eq. (1) gives

$$
\sigma_{F A}=\sigma_{\alpha^{*}} / \sqrt{2}
$$

From the derivation in the Appendix it can be seen that

$$
\sigma_{\alpha^{*}} \sim \sigma_{C_{N}} / C_{N_{\alpha}}
$$

where the proportionality constant depends on the details of the FA measurement process and the amount of $C_{N}$ across-run variation compared to the point-to-point within-run variation. Substituting Eq. (20) into Eq. (19) gives

$$
\sigma_{F A} \sim \sigma_{C_{N}} / C_{N_{\alpha}}
$$

Hence, the FA repeatability for a customer test would be predicted by 


$$
\sigma_{F A, \text { customer }}=\sigma_{F A, P F I} \frac{\sigma_{C_{N, \text { customer }}}}{\sigma_{C_{N, P F I}}} \frac{C_{N_{\alpha, P F I}}}{C_{N_{\alpha, \text { customer }}}}
$$

For the present analysis, it is assumed that the same or equivalent balance is used for the PFI and customer tests. Hence, the first ratio is simply

$$
\frac{\sigma_{C_{N, \text { customer }}}}{\sigma_{C_{N, P F I}}}=\frac{S_{R, P F I}}{S_{R, \text { customer }}}
$$

Substituting Eq. (23) into Eq. (22) gives

$$
\sigma_{F A \text {, customer }}=\sigma_{F A, P F I} \frac{S_{R, P F I}}{S_{R, \text { customer }}} \frac{C_{N_{\alpha, P F I}}}{C_{N_{\alpha, \text { customer }}}}
$$

or, using Eq. (13), Eq. (24) becomes

$$
R_{\mathrm{fit}, \text { customer }}=R_{\mathrm{fit}, P F I} \frac{S_{R, P F I}}{S_{R, \text { customer }}} \frac{C_{N_{\alpha, P F I}}}{C_{N_{\alpha, \text { customer }}}}
$$

The slope, $C_{N_{\alpha \text {, customer }}}$, must come from measurement or analytical prediction.

For testing with other NTF balances, the modest evidence of Ref. 13 suggests that the scaling would also involve the full-scale limits and spring constants of the PFI and customer balances. In either case, quality assurance would be manifested by showing that the subgroup ranges measured during the customer test fall roughly around the predicted value of $R_{\text {fit }}$ with none above the upper critical limit as discussed above.

\section{Example Application}

A recent test (148) in the NTF used the NTF 113B balance which is supposed to have the same characteristics as the NTF 113C. In addition, the reference area and $C_{N_{\alpha}}$ values are quite different from those of the PFI. For $q_{\infty}>290$ psf and using Eq. (6), Eq. (25) becomes

$$
R_{\mathrm{fit}, \text { customer }}=0.00246 \mathrm{deg}\left(\frac{1.988 \mathrm{ft}^{2}}{5.563 \mathrm{ft}^{2}}\right)\left(\frac{0.140 \mathrm{deg}^{-1}}{0.082 \mathrm{deg}^{-1}}\right)=0.00150 \mathrm{deg}
$$

For $q_{\infty} \leq 290$ psf and using Eq. (5), Eq. (25) becomes

$$
R_{\text {fit, customer }}=\frac{0.714 \mathrm{deg}-\mathrm{psf}}{q_{\infty}}\left(\frac{1.988 \mathrm{ft}^{2}}{5.563 \mathrm{ft}^{2}}\right)\left(\frac{0.140 \mathrm{deg}^{-1}}{0.082 \mathrm{deg}^{-1}}\right)=0.436 \mathrm{deg}-\mathrm{psf} / q_{\infty}
$$

Fourteen FA subgroups were obtained in customer test 148 . The ranges obtained were normalized appropriately by either Eq. (26) or Eq. (27) and are shown in Fig. 12, together with the predicted centerline and the upper limit used earlier (99.5\%). The measured values appear to be reasonable with respect to the predictions. The ranges are shown in the order in which they were obtained with 3 obtained for $q_{\infty} \leq 290$ psf and 5 obtained at cryogenic conditions. There seems to be no significant difference between the air (warm) and nitrogen (cold) measurements. The average of the 14 normalized range measurements is 1.02 which is not significantly different from the prediction. Consequently, the predictions should be used for post-test analysis and reporting of measurement uncertainty. 


\section{Conclusions}

For the first time, a complete quality assurance process has been demonstrated for wind tunnel FA measurements. Also, for the first time, a single characterization of flow angularity repeatability has been developed and checked for statistical consistency. For the test conditions that are typical for transonic cruise performance testing, Eq. (7) shows that the confidence interval for the repeatability at $\pm 2 \sigma$ coverage is \pm 0.0044 deg about a single measurement, which is well within the required tolerance band of $\pm 0.01 \mathrm{deg}$. Increasing the confidence interval to account for the reproducibility within a test still leaves the interval within the required tolerance band. In addition, for the first time, check standard repeatability results were successfully scaled to a customer test with very different properties. Finally, it should be pointed out that the resources required to obtain the check standard data and to carry out the analysis are quite reasonable from both the facility and the customer viewpoints.

\section{Appendix}

Consider the following linear regression model for the set of data $\left(\alpha_{i}, C_{N, i}\right)$ :

$$
C_{N}=C_{N_{0}}+C_{N_{\alpha}} \alpha
$$

Equation (28) gives a point estimate of the mean of $C_{N}$ for a particular value of $\alpha$ and the variance of $C_{N}$ is $\sigma_{C_{N}}^{2}$. Solving Eq. (28) for a particular value of the dependent variable, $\alpha^{*}$, gives Eq. (2). Error propagation applied to Eq. (2) gives $^{19}$

$$
\sigma_{\alpha^{*}}=\sqrt{\sigma_{C_{N_{0}}}^{2}+\alpha^{* 2} \sigma_{C_{N_{\alpha}}}^{2}} / C_{N_{\alpha}}
$$

It is shown in Ref. 20 that

$$
\begin{aligned}
\sigma_{C_{N_{0}}} & =\sigma_{C_{N}} \sqrt{1 / n+\bar{\alpha}^{2} / S_{\alpha \alpha}} \\
\sigma_{C_{N_{\alpha}}} & =\sigma_{C_{N}} / S_{\alpha \alpha}^{1 / 2}
\end{aligned}
$$

where

$$
S_{\alpha \alpha}=\sum_{i=1}^{n}\left(\alpha_{i}-\bar{\alpha}\right)^{2}
$$

Substituting Eqs. (30) into Eq. (29) gives

$$
\sigma_{\alpha^{*}}=\frac{\sigma_{C_{N}}}{C_{N_{\alpha}}} \sqrt{\frac{1}{n}+\frac{\bar{\alpha}^{2}+\alpha^{* 2}}{S_{\alpha \alpha}}}
$$

or

$$
\sigma_{\alpha^{*}} \sim \sigma_{C_{N}} / C_{N_{\alpha}}
$$

which is Eq. (20).

\section{Acknowledgments}

The author is grateful to the staff of the National Transonic Facility and to Dr. E. L. Walker for conducting the check standard model tests and for supplying the repeatability results and to M. Carter of the Configuration Aerodynamics Branch for supplying the repeatability data from test 148. 


\section{References}

${ }^{1}$ Steinle, F., and Stanewsky, E., Wind Tunnel Flow Quality and Data Accuracy Requirements, AGARD-AR-184, November 1982.

${ }^{2}$ Finley, T. D. and Tcheng, P., "Model Attitude Measurements at NASA Langley Research Center, AIAA-1992-0763, January 1992.

${ }^{3}$ Tripp, J. S., and Tcheng, P., "Uncertainty Analysis of Inertial Model Attitude Sensor Calibration and Application with a Recommended New Calibration Method,” NASA/TP-1999-209835, December 1999.

${ }^{4}$ Tcheng, P., Tripp, J. S., and Finley, T. D., "Effects of Yaw and Pitch Motion on Model Attitude Measurements, NASA TM 4641, February 1995.

${ }^{5}$ Crawford, B. L., and Finley, T. D., "Improved Correction System for Vibration Sensitive Inertial Angle-of-Attack Measurement Devices,” AIAA-2000-0415, January 2000.

${ }^{6}$ Crawford, B. L., and Finley, T. D., "Results from a Sting-Whip-Correction Verification Test in the Langley 16-Foot Transonic Tunnel,” AIAA-2002-0879, January 2002.

${ }^{7}$ Walker, E. L., "Statistical Calibration and Validation of a Homogeneous Ventilated-Wall Interference Correction Method for the National Transonic Facility,” Ph.D. Thesis, Virginia Polytechnic Institute and State University, Blacksburg, VA, October 2005. (Available at http://scholar.lib.vt.edu/theses/available/etd-10272005-165559/)

${ }^{8}$ Anon., “AIAA Recommended Practice for the Calibration of Subsonic and Transonic Wind Tunnels,” AIAA R-093-2003, 2004.

${ }^{9}$ Kimothi, S. K.., The Uncertainty of Measurements, ASQ Quality Press, 2002.

${ }^{10}$ Anon., "U.S. Guide to the Expression of Uncertainty in Measurement,” ANSI/NCSL Z540-2-1997, October 1997.

${ }^{11}$ Wahls, R. A., "The National Transonic Facility: A Research Retrospective,” AIAA-2001-0754, January 2001.

${ }^{12}$ Kilgore, W. A., Balakrishna, S., Bobbitt, C. W., and Underwood, P., "Recent Enhancements to the National Transonic Facility, AIAA-2003-0754, January 2003.

${ }^{13}$ Hemsch, M. J., Tuttle, D. G., Houlden, H. P., and Graham, A. B., “Measurement of Force Balance Repeatability and Reproducibility in the NTF,” AIAA-2004-0771, January 2004.

${ }^{14}$ Montgomery, D. C., Introduction to Statistical Quality Control, 3rd Ed., Wiley, 1996.

${ }^{15}$ Mosteller, F, and Tukey, J. W., Data Analysis and Regression: A Second Course in Statistics, Addison-Wesley, 1977.

${ }^{16}$ Wheeler, D. J., Range Based Analysis of Means, SPC Press, Knoxville, TN, 2003.

${ }^{17}$ Owen, D. B., Handbook of Statistical Tables, Addison-Wesley, 1962.

${ }^{18}$ Eisenhart, C., "Realistic Evaluation of the Precision and Accuracy of Instrument Calibration Systems,” J. Research National Bureau of Standards - C, Vol. 67C, No.2, April-June 1963.

${ }^{19}$ Coleman, H. W., and Steele, W. G., Experimentation and Uncertainty Analysis for Engineers, 2nd Ed., Wiley, 1999.

${ }^{20}$ Montgomery, D. C., Peck, E. A., and Vining, G. G., Introduction to Linear Regression Analysis, 3rd Ed., Wiley, 2001. 


\begin{tabular}{|c|c|c|c|c|c|c|c|c|c|c|}
\hline$M_{\infty}$ & $\begin{array}{c}q_{\infty}, \\
\mathrm{psf}\end{array}$ & $\begin{array}{c}p_{T_{\infty}}, \\
\mathrm{psia}\end{array}$ & \multicolumn{2}{|c|}{$\begin{array}{c}\text { Test } 121 \\
\text { Oct } 2001\end{array}$} & \multicolumn{2}{|c|}{$\begin{array}{c}\text { Test 137 } \\
\text { Apr } 2002\end{array}$} & \multicolumn{2}{|c|}{$\begin{array}{c}\text { Test } 149 \\
\text { Jun 2004 }\end{array}$} & \multicolumn{2}{c|}{$\begin{array}{c}\text { Test } 156 \\
\text { Feb } 2005\end{array}$} \\
\hline & & & & $\hat{\sigma}_{\Delta F A \text {, actual }}$ & & $\hat{\sigma}_{\Delta F A \text {, actual }}$ & & $\hat{\sigma}_{\Delta F A \text {, actual }}$ & & $\hat{\sigma}_{\Delta F A \text {, actual }}$ \\
\hline 0.091 & 15 & 18.0 & $\mathrm{X}$ & 0.623 & $\mathrm{X}$ & 0.646 & & & & \\
\hline 0.138 & 34 & 18.0 & $\mathrm{X}$ & 1.300 & $\mathrm{X}$ & 0.433 & & & & \\
\hline 0.209 & 77 & 18.0 & $\mathrm{X}$ & 1.190 & $\mathrm{X}$ & 0.831 & & & & \\
\hline 0.189 & 176 & 50.0 & $\mathrm{X}$ & 0.298 & $\mathrm{X}$ & 0.509 & & & $\mathrm{X}$ & 0.338 \\
\hline 0.289 & 398 & 50.0 & $\mathrm{X}$ & 1.945 & $\mathrm{X}$ & 1.087 & & & $\mathrm{X}$ & 1.804 \\
\hline 0.600 & 676 & 23.8 & & & & & $\mathrm{X}$ & --- & & \\
\hline 0.800 & 676 & 16.0 & & & & & $\mathrm{X}$ & --- & $\mathrm{X}$ & 0.845 \\
\hline 0.454 & 904 & 50.0 & $\mathrm{X}$ & 2.354 & $\mathrm{X}$ & 1.205 & $\mathrm{X}$ & --- & & \\
\hline 0.800 & 904 & 21.4 & & & & & $\mathrm{X}$ & --- & $\mathrm{X}$ & 0.850 \\
\hline 0.600 & 1425 & 50.0 & $\mathrm{X}$ & 1.404 & $\mathrm{X}$ & 1.325 & $\mathrm{X}$ & --- & & \\
\hline 0.800 & 1425 & 33.7 & & & & & $\mathrm{X}$ & --- & $\mathrm{X}$ & 0.838 \\
\hline 0.600 & 1690 & 59.4 & & & & & $\mathrm{X}$ & --- & & \\
\hline 0.800 & 1690 & 39.9 & & & $\mathrm{X}$ & 1.497 & $\mathrm{X}$ & --- & $\mathrm{X}$ & 0.719 \\
\hline 0.500 & 2414 & 113.7 & & & $\mathrm{X}$ & 1.567 & & & $\mathrm{X}$ & 1.049 \\
\hline
\end{tabular}

Table 1. Test section conditions for the check standard model tests (air).

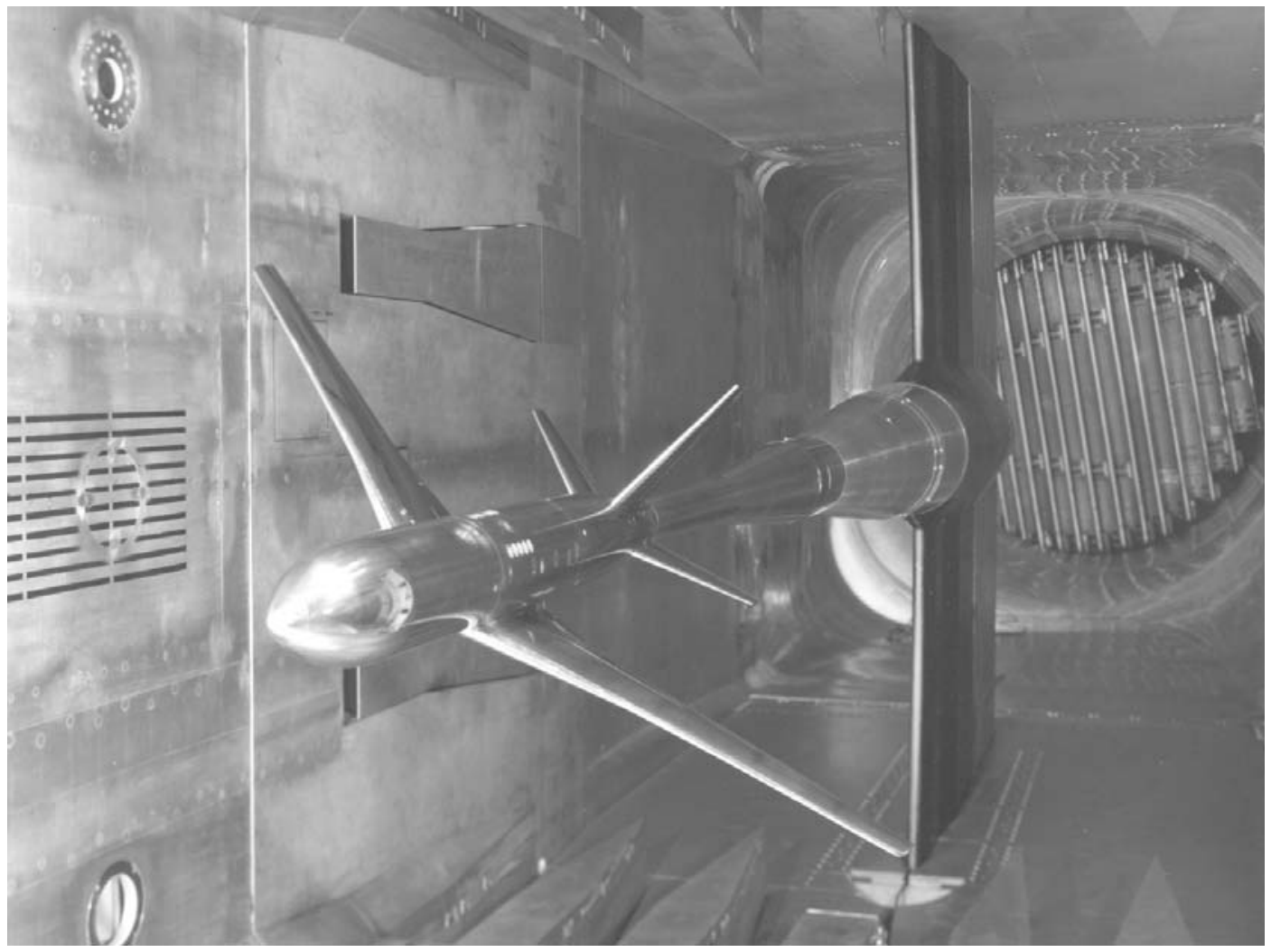

Figure 1. Photograph of the Pathfinder I model mounted in the NTF showing the remote roll capability. 


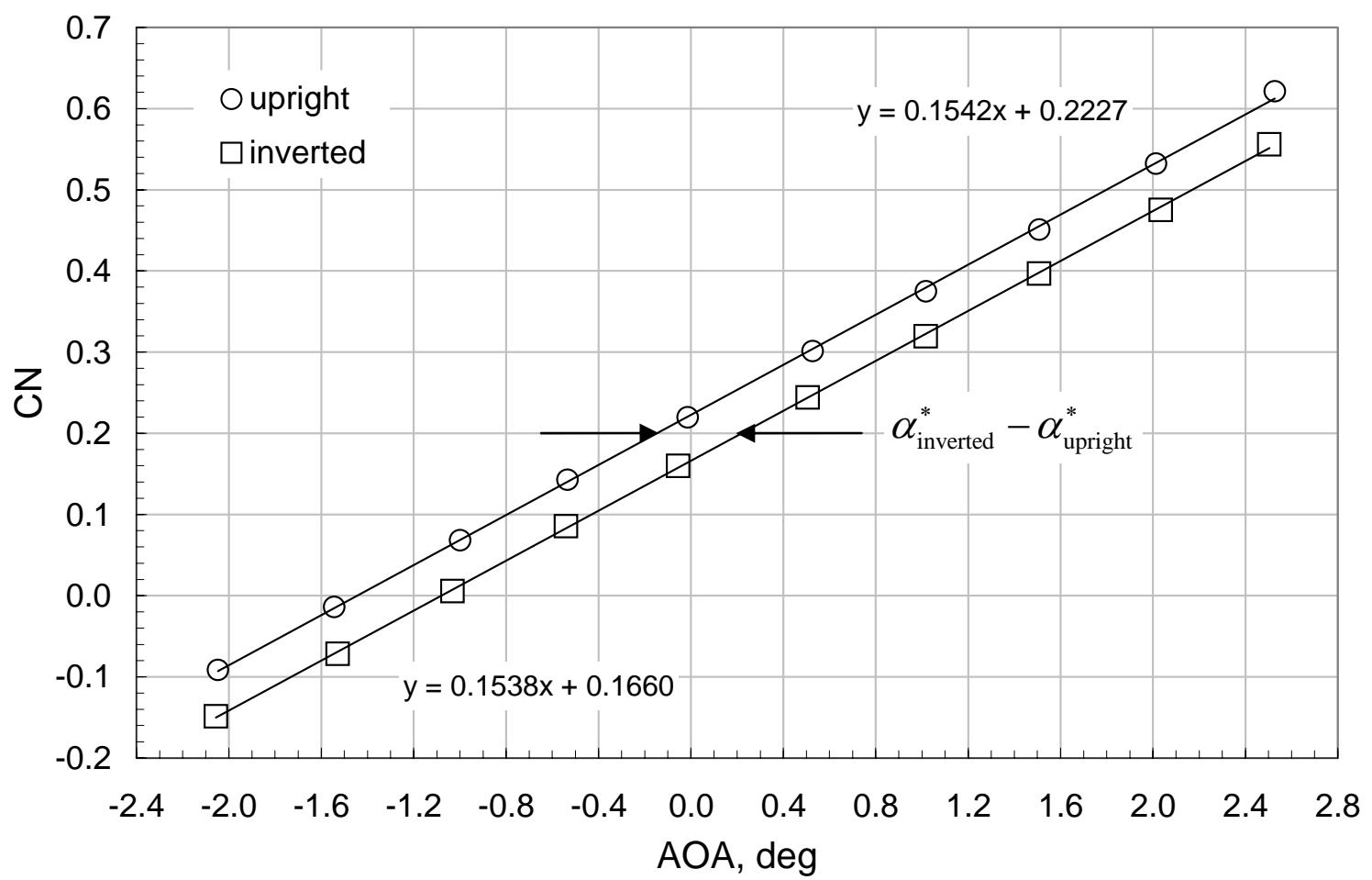

Figure 2. Typical upright/inverted run set and fits for FA estimate (T156, Runs 245 and 246).

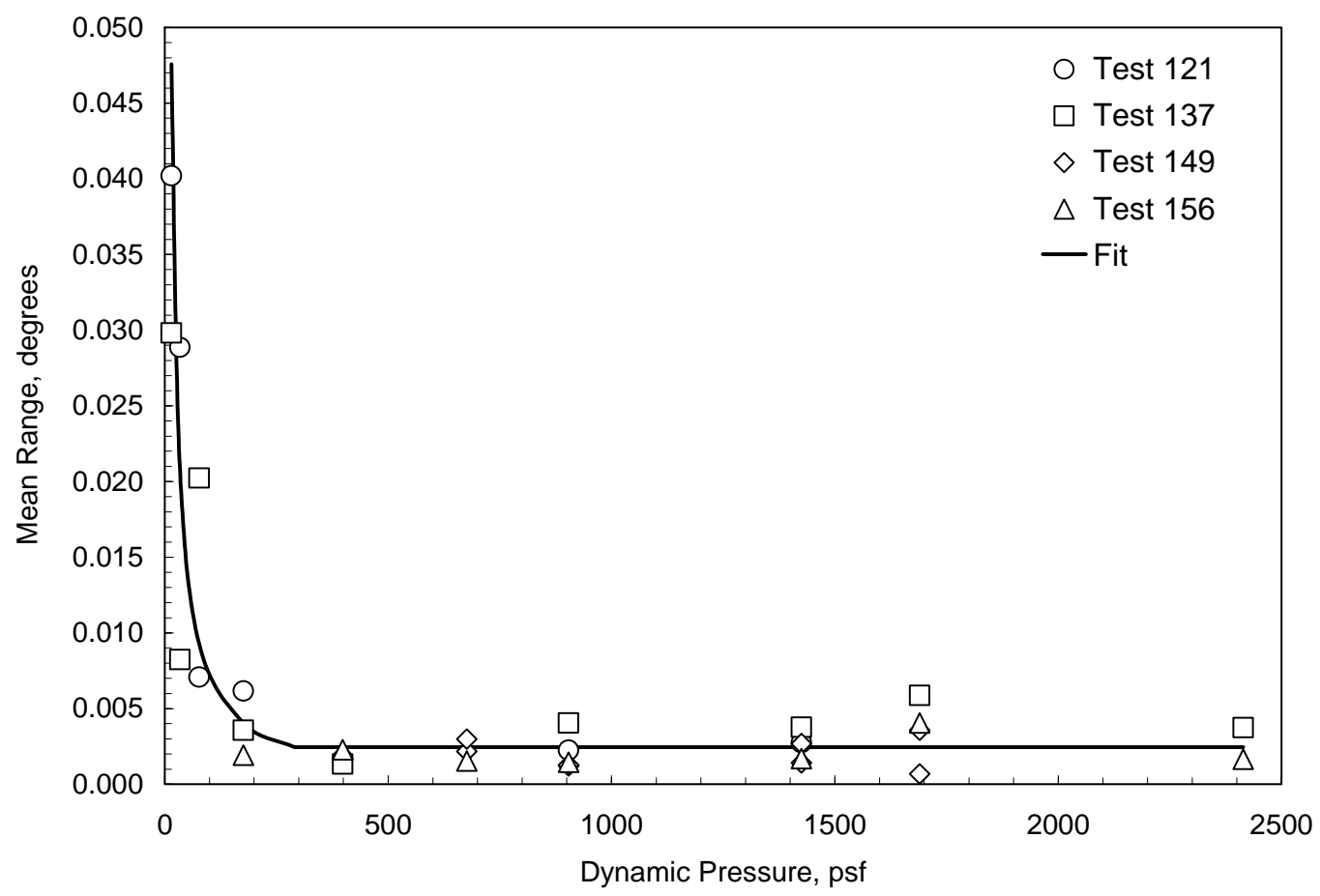

Figure 3. Dependence of FA mean range on $q_{\infty}$ for tests 121, 137, 149, 156. 


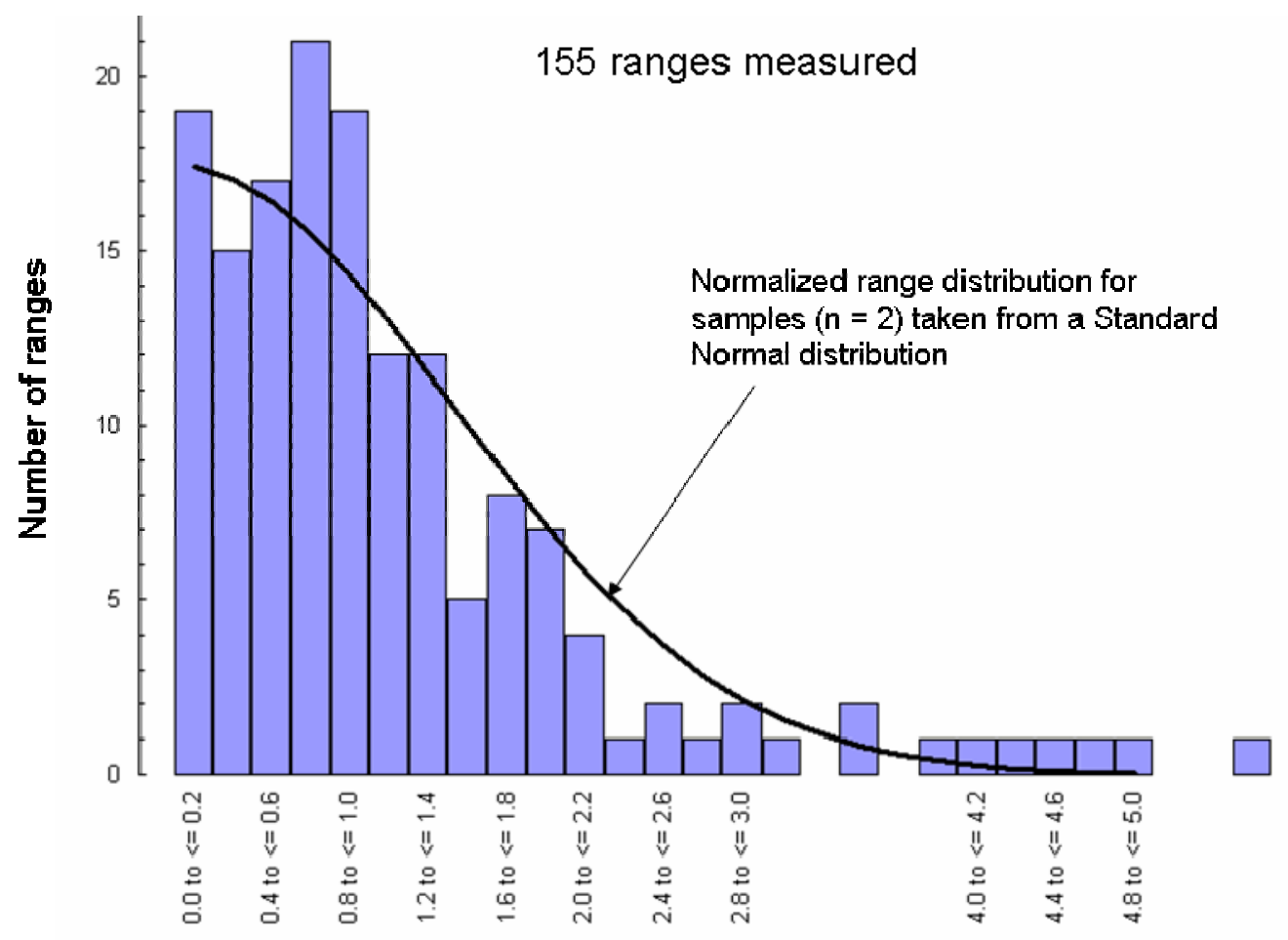

Figure 4. Distribution of FA ranges normalized by the fit.

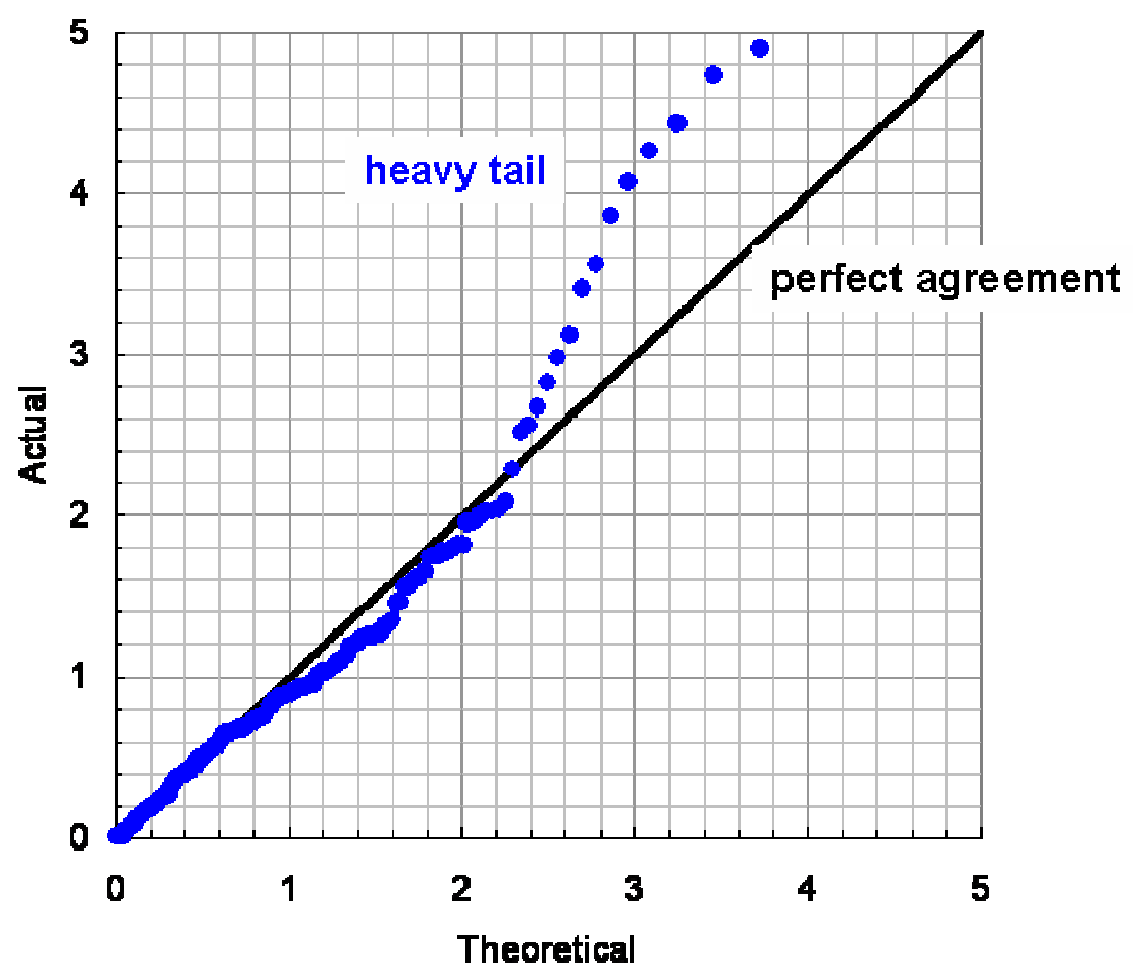

Figure 5. Probability plot for the normalized ranges. 


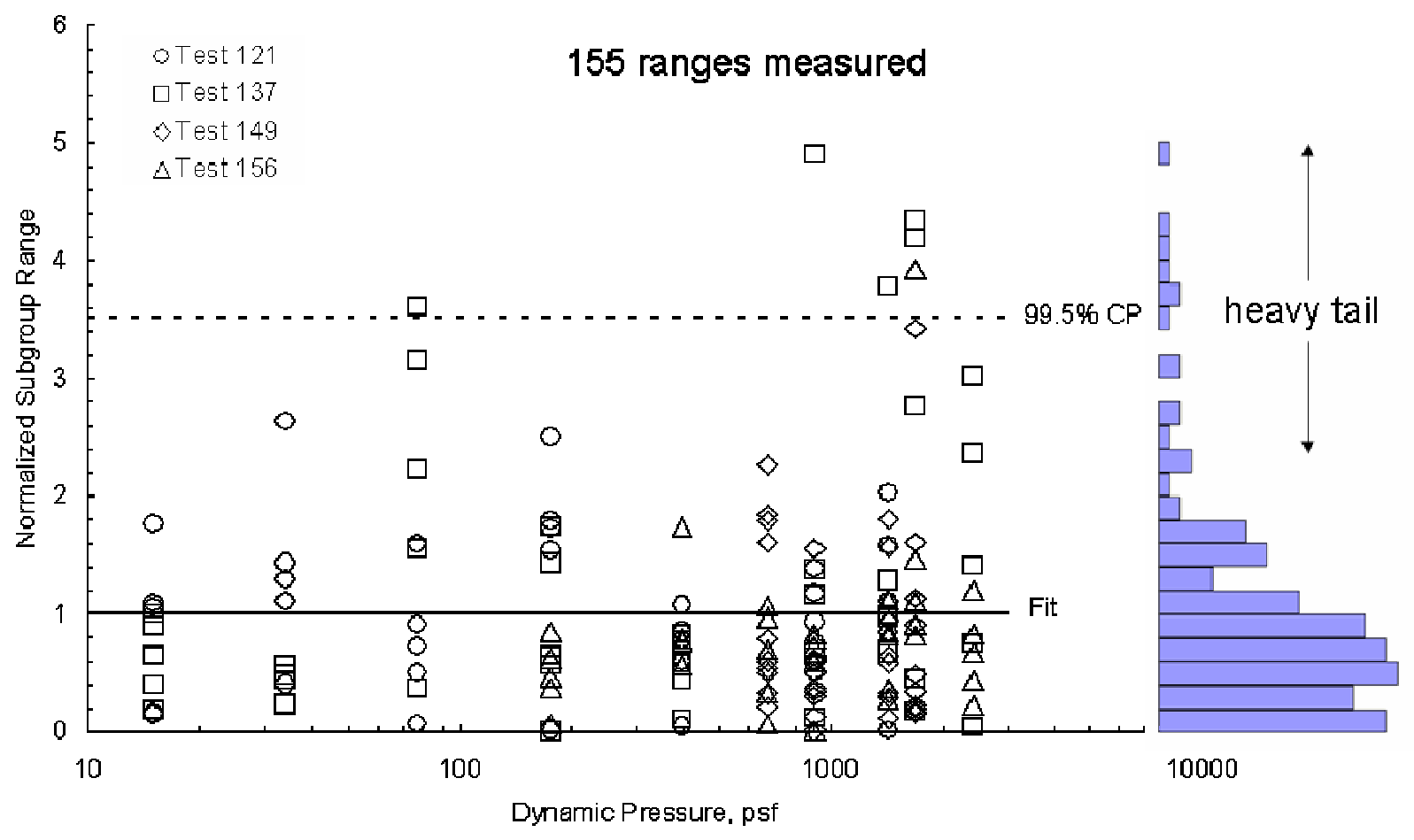

Figure 6. Distribution of normalized ranges as a function of dynamic pressure/

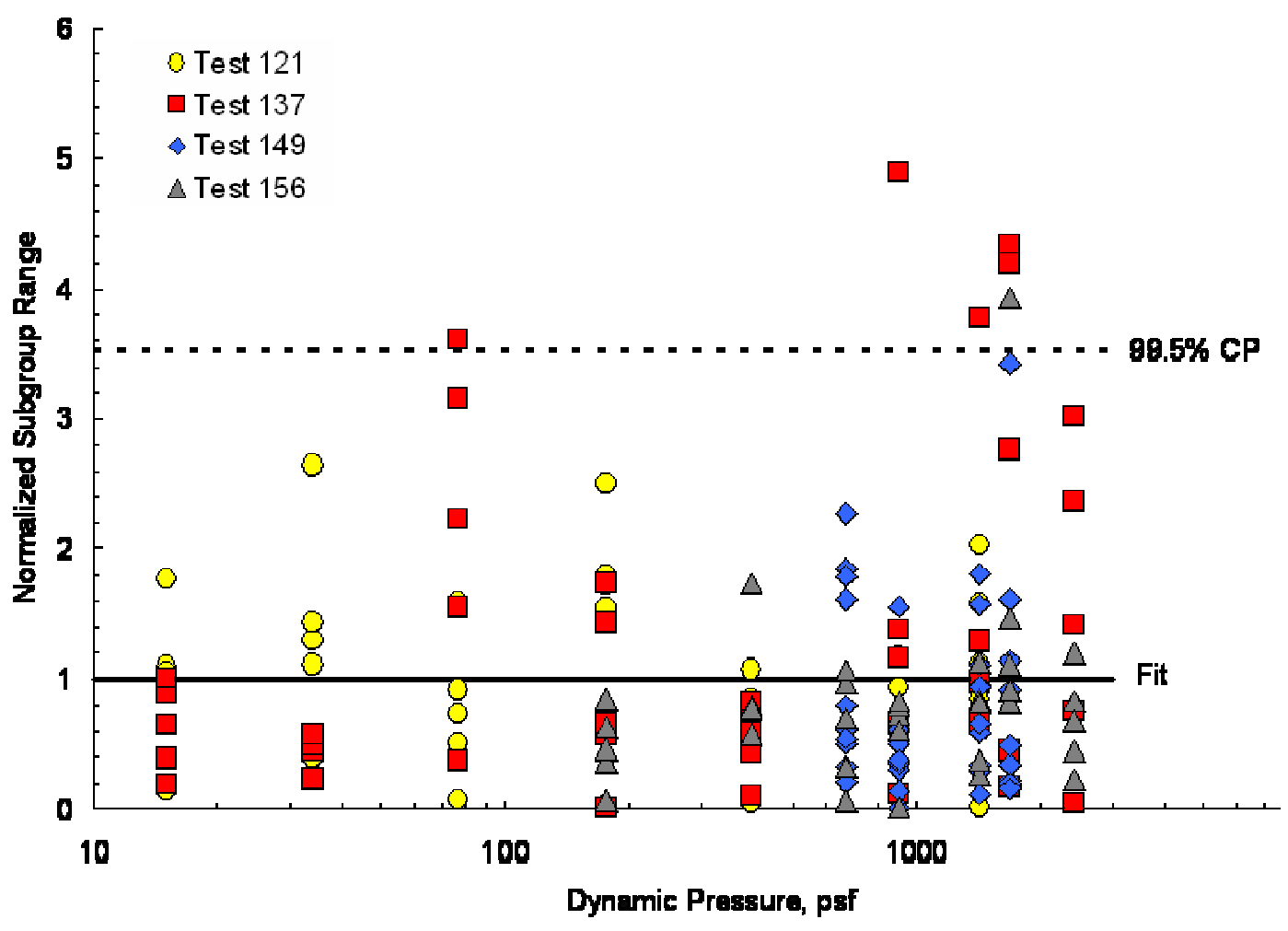

Figure 7. Distribution of normalized ranges as a function of dynamic pressure and test. 

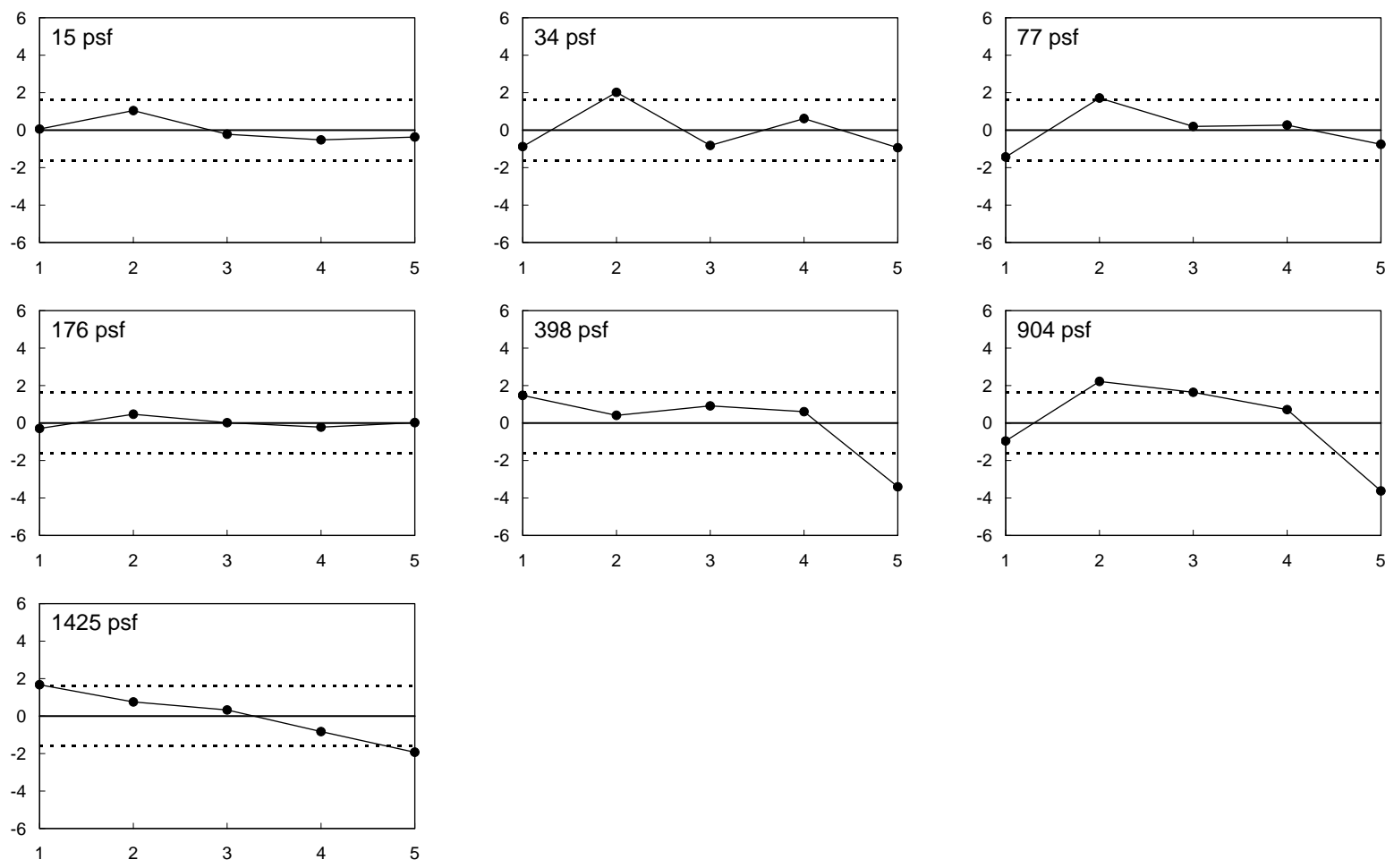

Figure 8. Variation of flow angularity subgroup averages during test $121,(\overline{F A}-\overline{\overline{F A}}) / R_{\text {fit }}$ versus group number.
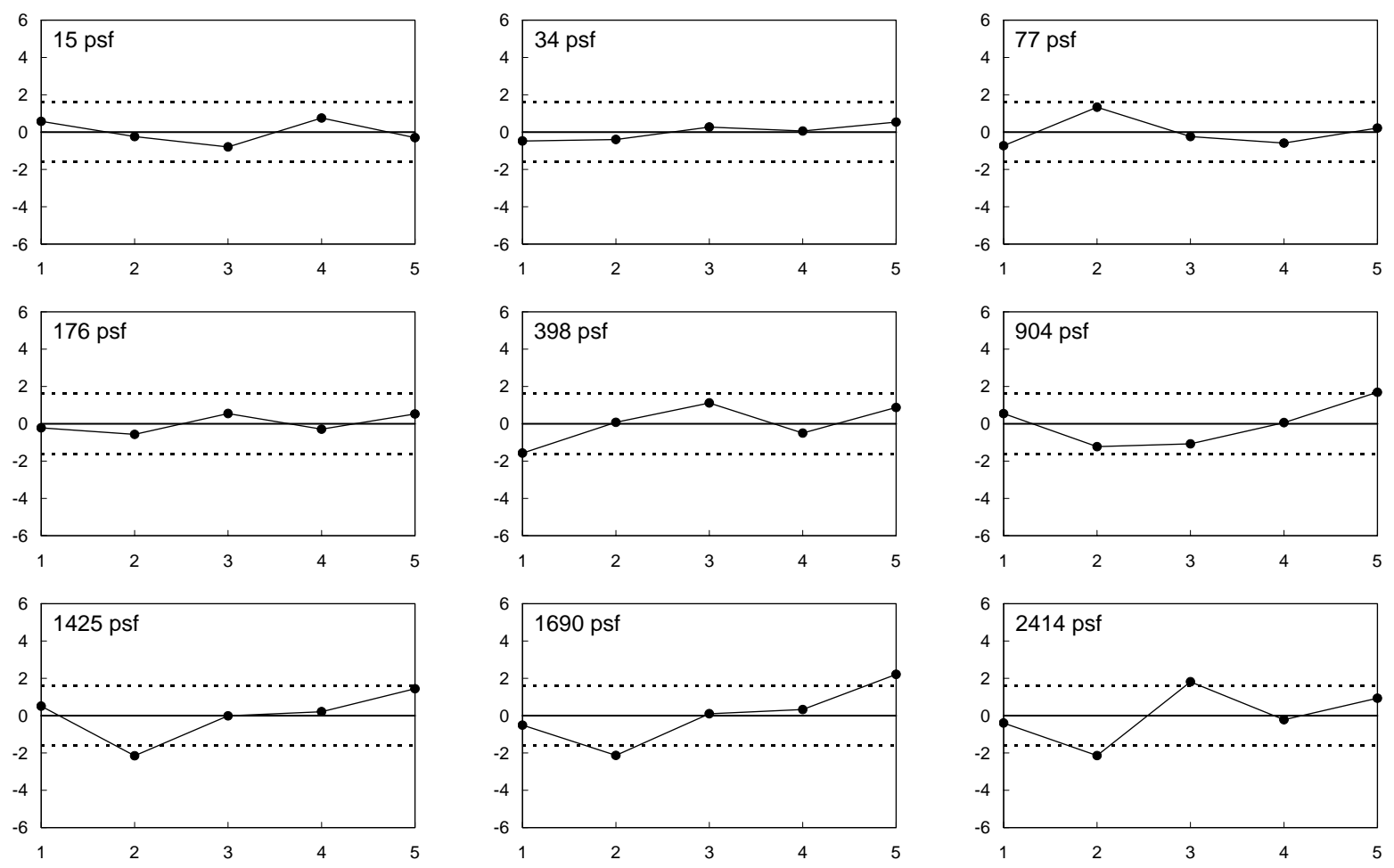

Figure 9. Variation of flow angularity subgroup averages during test $137,(\overline{F A}-\overline{\overline{F A}}) / R_{\text {fit }}$ versus group number. 

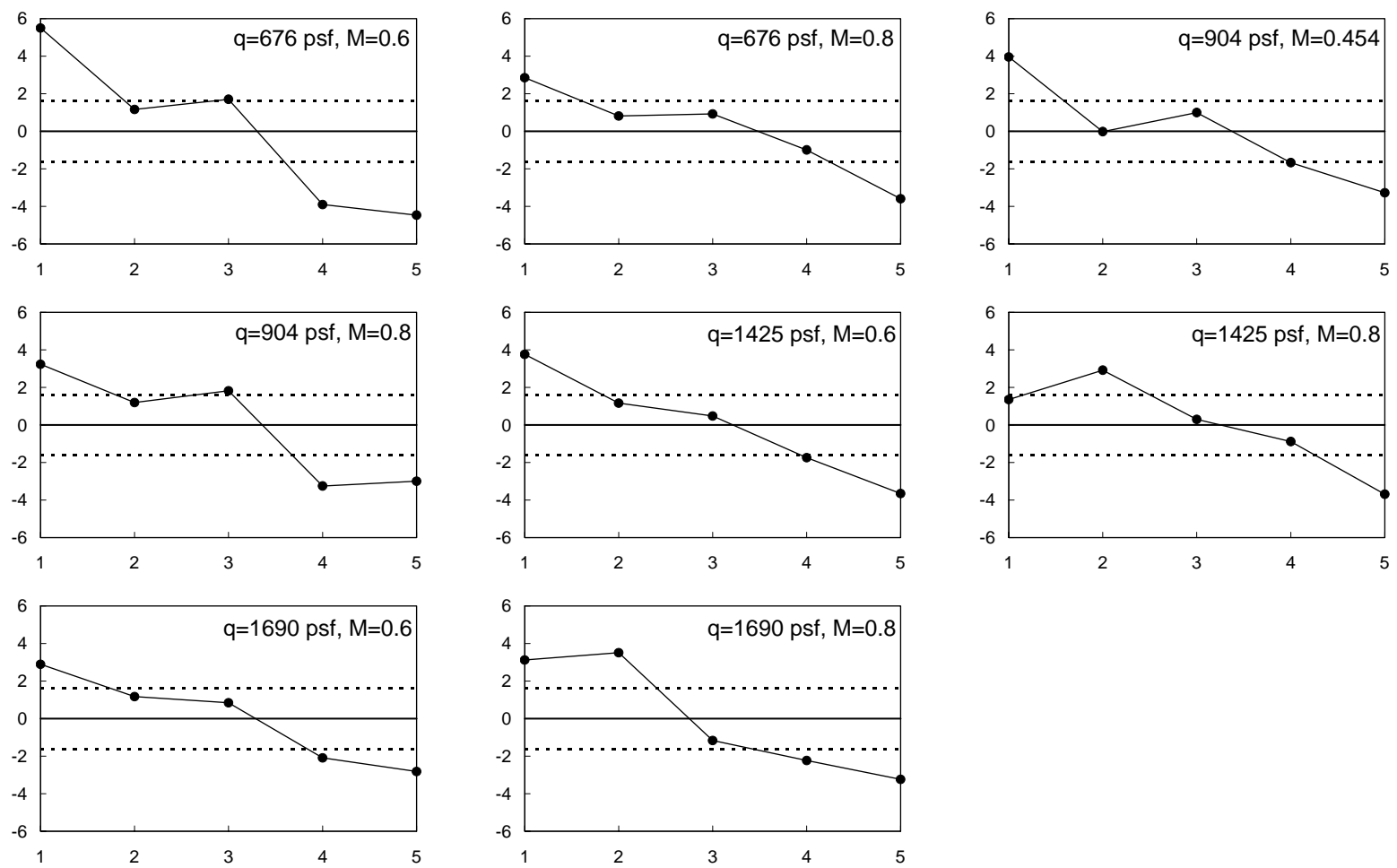

Figure 10. Variation of flow angularity subgroup averages during test $149,(\overline{F A}-\overline{\overline{F A}}) / R_{\text {fit }}$ versus group number.
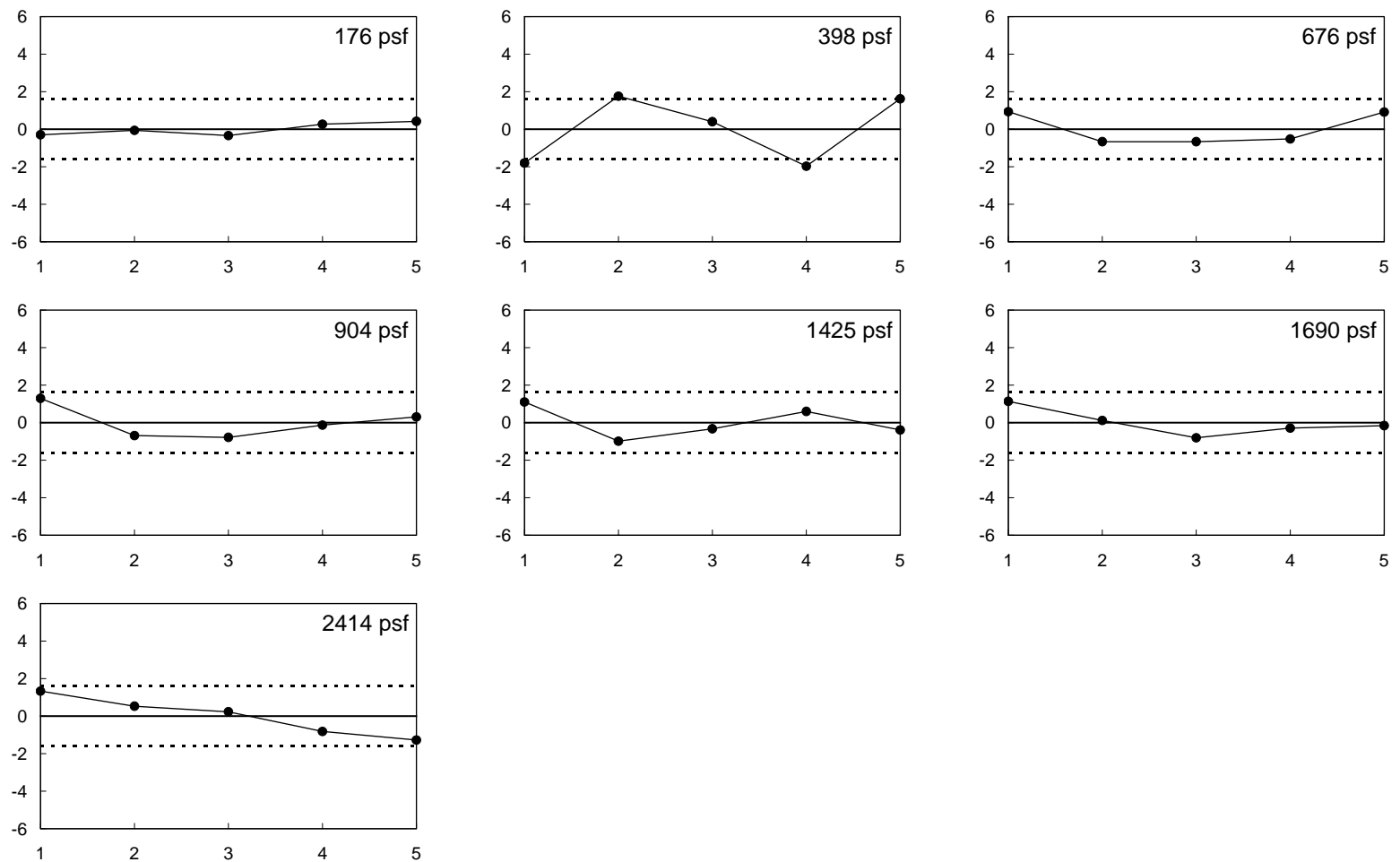

Figure 11. Variation of flow angularity subgroup averages during test $156,(\overline{F A}-\overline{\overline{F A}}) / R_{\mathrm{fit}}$ versus group number. 


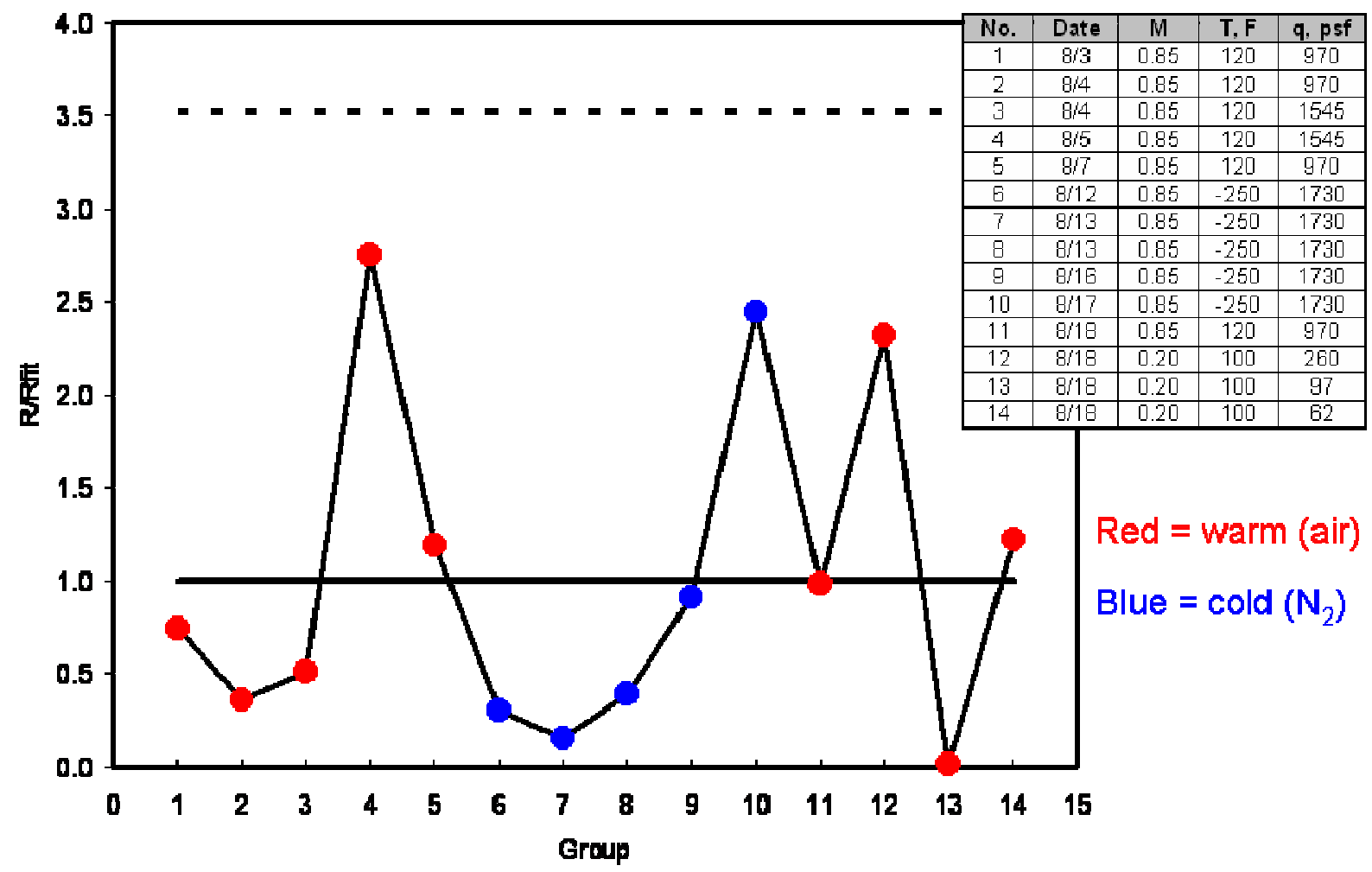

Figure 12. FA ranges from Test 148 normalized by fit from check standard tests. 